\title{
MicroRNA-205-5b inhibits HMGB1 expression in LPS-induced sepsis
}

\author{
WENHAI ZHOU ${ }^{1}$, JING WANG $^{1}$, ZHIFENG LI $^{1}$, JIANGUO LI $^{1}$ and MING SANG ${ }^{2}$ \\ ${ }^{1}$ Department of Intensive Care Unit, Zhongnan Hospital of Wuhan University, Wuhan, Hubei 430071; ${ }^{2}$ Central Laboratory of \\ The Fourth Affiliated Hospital in Xiangyang, College of Basic Medical Sciences, Hubei Key Laboratory of \\ Wudang Local Chinese Medicine Research, Hubei University of Medicine, Shiyan, Hubei 442000, P.R. China
}

Received August 31, 2015; Accepted May 9, 2016

DOI: $10.3892 / \mathrm{ijmm} .2016 .2613$

\begin{abstract}
Inflammatory cytokines belonging to high mobility group box (HMGB)1 play a key role in sepsis through yet unknown mechanisms. The inflammatory response is modulated by microRNAs (miRNAs or miRs) at multiple levels and is poorly understood. In this study, the regulation of HMGB1 by miRNAs was evaluated using 3-(2,4-dimethoxybenzylidene) anabaseine (GTS-21) to activate the cholinergic anti-inflammatory pathway (CAP) and decrease HMGB1 expression in RAW264.7 cells. Microarray-based miRNA expression profiling of RAW264.7 cells was used to screen target miRNAs through genetic screening, GO analysis and hierarchical clustering. The expression of miRNA targets in the serum, colon, spleen, livers and lungs of BALB/c mice was quantified by RT-qPCR. Serum protein levels were quantified by ELISA. Western blot analysis and RT-qPCR were used for verification in vitro. Using miRNA array analysis, we screened 3 miRNAs (miR-205-5b, miR-196a and miR-193b). Animal experiments with miR-205-5b indicated its high degree of expression in the serum, colon, spleen, liver and lungs following the downregulation of HMGB1 in the tissues. RAW264.7 cells transfected with miR-205-5b mimics downregulated HMGB1 protein expression, suggesting translational regulation. HMGB1 expression negatively correlated with miR-205-5b expression in LPS-induced sepsis. By contrast, HMGB1 expression in LPS-stimulated RAW264.7 cells was increased following transfection with miR-205-5b inhibitor. miR-205-5b is a critical mediator of cholinergic anti-inflammatory activity in late sepsis. The upregulation of miR-205-5b as a potential therapeutic target for the treatment of inflammatory diseases is a possible novel therapeutic strategy against late sepsis. The mechanisms involved include the by post-transcriptional suppression of HMGB1 in cells and tissues.
\end{abstract}

Correspondence to: Dr Jianguo Li, Department of Intensive Care Unit, Zhongnan Hospital of Wuhan University, 169 Donghu Road, Wuhan, Hubei 430071, P.R. China

E-mail: drljg2011@whu.edu.cn

Key words: microRNA-205-5b, high mobility group box 1, sepsis, cholinergic anti-inflammatory pathway

\section{Introduction}

Sepsis is one of the common causes of death in intensive care unit (ICU) patients. As inflammation spreads into the bloodstream, the deregulated production of cytokines, such as tumor necrosis factor (TNF)- $\alpha$ and interleukin (IL)-1b, triggers high mobility group box (HMGB)1 expression as a late mediator of inflammation (1). Systemic and persistent inflammation may lead to organ dysfunction and ultimately, death $(2,3)$. Despite evidence suggesting that TNF- $\alpha$, IL-1b and HMGB1 are associated with endotoxin lethality and septic syndrome, unfortunately, monoclonal antibodies against TNF- $\alpha$ and TNF-binding proteins fail to decrease sepsis (2).

Despite the availability of 170 different biomarkers, the complex clinical syndrome of sepsis and related mortality have increased in incidence (4). Microbial infection underlying sepsis accounts for an almost $30 \%$ increase in mortality, despite advances in antimicrobial research (5). The majority of studies on sepsis have focused on biomarkers for early diagnosis, treatment or prognosis. Treatment is very unsatisfactory, as early inflammatory cytokines are restored to their basic levels only after sepsis-related death (9).

A more appropriate cytokine to block sepsis includes the late onset inflammatory mediator, HMGB1, a crucial late-phase cytokine in the course of sepsis (6). A high level of HMGB1 is associated with a poor outcome in sepsis (7). Superfluous HMGB1, secreted by macrophages and monocytes, plays a key role in the pathogenesis of sepsis due to bacterial infections (7), as well as in cancers (8). Future breakthroughs in sepsis treatment may depend on addressing the issue of the production of late inflammatory cytokines, such as HMGB1 (9).

As non-coding transcripts of 18-25 nucleotides, microRNAs (miRNAs or miRs) usually target mRNAs to modulate gene expression by 1.2- to 4.0-fold rather than acting as a genetic switch (10). Several miRNAs have been shown to regulate sepsis by targeting different mRNAs. The suppression of the expression of miR-15a/16 in bone marrow-derived macrophages caused by bacterial-derived lipopolysaccharide (LPS) has been shown to increase phagocytosis and bacterial clearance through Toll-like receptor (TLR) 4-associated pathways, subsequently affecting the survival of septic mice (11). miR-147b represents an endothelial barrier of protection against endotoxin-mediated inflammation by decreasing 
ADAM metallopeptidase domain 15 (ADAM15) expression and attenuating LPS-induced barrier dysfunction during septic challenge by bacterial LPS in endothelial cells (12). Serum levels of miR-122 have been shown to be increased in patietns with sepsis with clotting abnormalities (13). miR-133a levels have also been shown to correlate with the severity of sepsis and, at significantly higher levels, predicted an unfavorable prognosis of critically ill patients (14).

The cholinergic anti-inflammatory pathway (CAP) is a mechanism associated with the vagus nerve. CAP plays a critical role in controlling the inflammatory response by modulating systemic and local inflammation (15). Its molecular mechanisms of action are mediated by the major neurotransmitter, acetylcholine, which activates the nicotinic acetylcholine receptor subunit $\alpha 7$ ( $\alpha 7 \mathrm{nAchR}) . \alpha 7 \mathrm{nAchR}$ is expressed on macrophages and is an essential component of CAP (3). 3-(2,4-Dimethoxybenzylidene)anabaseine (GTS-21) is an $\alpha 7 n$ AchR-specific agonist (16). miR-124 reduces early inflammatory cytokine levels in the cholinergic anti-inflammatory response. miR-124 reduces IL- 6 production by affecting the signal transducer and activator of transcription 3 (STAT3), and attenuates the release of TNF- $\alpha$ via TNF- $\alpha$ converting enzyme (TACE) (17).

The role of the late inflammatory cytokine HMGB1 as regards its regulation by miRNAs have yet to be reported in sepsis. In this study, using miRNA microarray analysis, we screened 3 target miRNAs: miR-205-5b, miR-196a and miR-193b. Of the 3 miRNAs, miR-205-5b was the most highly expressed followed by decreased HMGB1 levels. Given the important role of HMGB1 in sepsis (18), miR-205-5b is a potential biomarker or therapeutic target in sepsis. In this study, we elucidated the expression of miR-205-5b in different tissues using a mouse model of LPS-induced sepsis and identified the mechanisms of action of miR-205-5b action and its effects on HMGB1.

\section{Materials and methods}

Cell culture. The mouse macrophage cell line, RAW264.7, was obtained from the Medical Experimental Center of Zhongnan Hospital of Wuhan University. The RAW264.7 cells were cultured in DMEM with heat-inactivated $10 \%$ fetal bovine serum (FBS) (HyClone, Logan, UT, USA) and seeded into 48 -well microtiter plates at a density of $2 \times 10^{4}$ cells/well.

Enzyme-linked immunosorbent assay (ELISA). A $200 \mu \mathrm{l}$ supernatant was obtained at 1, 6, 12, 18, 24 and $30 \mathrm{~h}$ to confirm the optimal concentration. The levels of TNF- $\alpha$ and HMGB1 in the supernatant were determined by ELISA using a specific kit (eBioscience, Inc., San Diego, CA, USA) according to the manufacturer's instructions with a microplate reader (RT-2100C; Rayto, USA).

miRNA microarrays. Following culture of the RAW264.7 cells for $24 \mathrm{~h}$, cells in the LPS group were stimulated with $50 \mathrm{ng}$ / ml LPS (Sigma-Aldrich, St. Louis, MO, USA), those in the GTS-21 group with $50 \mathrm{ng} / \mathrm{ml}$ LPS and $8 \mu \mathrm{g} / \mathrm{ml}$ GTS-21 (Abcam, Cambridge, UK) at $24 \mathrm{~h}$, along with the control group (untreated cells) on an Affymetrix miRNA 3.0 technology platform, which contained 1,111 mature mouse miRNAs. NanoDrop ND-2100
(Thermo Fisher Scientific, Waltham, MA, USA) was used with Agilent 2100 (Agilent Technologies, Inc., Santa Clara, CA, USA) to identify and quantify the total RNAs and ensure their integrity.

Total RNA was tailed with with poly(A) polymerase and labeled with biotin, followed by hybridization, washing, staining and scanning with Affymetrix Scanner 3000 (Affymetrix, Inc., Santa Clara, CA, USA) to obtain the raw image. Raw image processing was performed using Affymetrix GeneChip Command Console software (version 4.0), read by Expression Console (version 1.3.1) (both from Affymetrix, Inc.) and RMA normalization. GeneSpring NGS (version 12.5) (Agilent Technologies) was used for subsequent data analysis. Probes meeting at least one out of two conditions and containing flags in ' $\mathrm{P}$ ' were selected for further analysis.

Differentially expressed miRNAs were then identified through fold change. The threshold set for upregulated and downregulated genes was a fold change $\geq 2.0$ and $\mathrm{p} \leq 0.05$. Target genes of differentially expressed miRNAs that represented the intersection of the 3 databases (TargeScan, PITA and microRNA.org) were selected as candidate target genes for further analysis. GO analysis and KEGG analysis were used to determine the roles of these target genes. Unsupervised hierarchical clustering was performed to show the distinguishable miRNA expression pattern among samples.

Experimental animals. We purchased 5-to 6-week-old BALB/c mice (weighing 20-22 g) from the Experimental Animal Center of Wuhan University, an accredited SPF facility according to national and institutional guidelines. The animals were bred under standard conditions with a temperature of $22^{\circ} \mathrm{C}$ with a 12-h light/dark cycle and had free access to water and a standard rodent diet. In addition, the animals received humane care in compliance with the Principles of Laboratory Animal Care of Wuhan University. All protocols were approved by the Wuhan University of Science and Technology Animal Care and Use Committee (certificate number: TY20120025).

Experimental protocols. The experimental animals were randomly divided into 3 groups as follows: the control, LPS, and GTS-21 treatment (LPS + GTS-21) groups, with 6 mice in each group.

In the LPS group, a single intraperitoneal injection of $15 \mathrm{mg} / \mathrm{kg}$ LPS was used to induce peripheral inflammation. The mice in the control group were treated similar to those in the LPS group, but received saline instead of LPS. In the GTS-21 treatment group, $15 \mathrm{mg} / \mathrm{kg}$ LPS and $4 \mathrm{mg} / \mathrm{kg}$ GTS-21 were injected into the mouse abdominal cavity.

Twenty-four hours after the intraperitoneal injection, blood, lungs, livers, colons and spleens were harvested immediately after the mice were euthanized. Blood was centrifuged at $3,000 \mathrm{rpm}$ for $10 \mathrm{~min}$ at $4^{\circ} \mathrm{C}$, to obtain the supernatant for further testing. Other tissues were stored in TRIzol for later use.

Reverse transcription-quantitative polymerase chain reaction $(R T-q P C R)$ for the determination of miRNA and $m R N A$ expression. Total RNA extracted from the lung, heart, liver, spleen, gut and renal tissues of the septic mice using TRIzol reagent (Invitrogen, Carslbad, CA, USA), and was reversetranscribed into cDNA using the RevertAid First Strand cDNA Synthesis kit (Thermo Fisher Scientific). qPCR for TNF- $\alpha$ 
Table I. Primers used for RT-qPCR.

\begin{tabular}{ll}
\hline Primers & \multicolumn{1}{c}{ Sequences } \\
\hline U6-S & 5'-CTCGCTTCGGCAGCACA-3' \\
U6-A & 5'-AACGCTTCACGAATTTGCGT-3' \\
M-miR-205-5p-RT & 5'-CTCAACTGGTGTCGTGGAGTCGGCAATTCAGTTGAGCAGACTCC-3' \\
M-miR-205-5p-S & 5'-ACACTCCAGCTGGGTCCTTCATTCCACCGG-3' \\
Universal primer & 5'-TGGTGTCGTGGAGTCG-3' \\
M-HMGB1-S & 5'-CGGATGCTTCTGTCAACTTCTC-3' \\
M-HMGB1-A & 5'-GTTTCTTCGCAACATCACCAAT-3' \\
M- $\beta$-actin-S & 5'-GTGACGTTGACATCCGTAAAGA-3' \\
M- $\beta$-actin-A & 5'-GTAACAGTCCGCCTAGAAGCAC-3' \\
\hline
\end{tabular}

and $\beta$-actin was performed using the 7300 Real-Time PCR system (Applied Biosystems Life Technologies, Foster City, CA, USA). The primer sequences were synthesized for TNF- $\alpha$ (Invitrogen). RT-qPCR was performed in triplicate and data were calculated using the $2^{-\Delta \Delta \mathrm{CT}}$ method, where $\Delta \Delta \mathrm{Ct}=\Delta \mathrm{Ct}-\Delta \mathrm{Ct}_{\mathrm{NC} \text { group }}, \Delta \mathrm{Ct}=\mathrm{Ct}_{\mathrm{miR}-205}-\mathrm{Ct}_{\mathrm{U} 6}$. The primers used for RT-qPCR are listed in Table I.

Transfection of miRNAs. The RAW264.7 cells were seeded into 6-well plates $\left(5 \times 10^{4}\right.$ cells/well) and cultured in $2 \mathrm{ml}$ Dulbecco's modified Eagle's medium (DMEM) with 5\% FBS, maintained at $37^{\circ} \mathrm{C}$ in the presence of $5 \% \mathrm{CO}_{2}$. miR-205 mimics, inhibitor and negative control were synthesized by GenePharma (Shanghai, China). When the cells reached 70-90\% confluency, they were transfected with miR-205 mimics or inhibitor, respectively according to the manufacturer's instructions with adherent cell transfection procedures. A negative control of Lipofectamine 2000 (Invitrogen) was maintained as well.

Western blot analysis. In order to obtain the total cellular lysates, the transfected cells and controls were lysed in ice-cold cell lysis buffer (Wuhan Goodbio Technology Co., Ltd., Wuhan, China). The protein concentration was determined using the Bradford protein assay kit (Bio-Rad Laboratories, Inc., Hercules, CA, USA) using a c-globulin standard curve. Proteins were separated by standard SDS-PAGE and transferred onto PVDF membranes (Millipore Corp., Billerica, MA, USA). Non-specific binding sites were blocked using 5\% dry skimmed milk, $0.2 \%$ Tween-20 in PBS (pH 7.4) and then incubated with HMGB1 antibodies (Boster Inc., Wuhan, China) overnight at $4^{\circ} \mathrm{C}$. The PVDF membranes were decolorized 3 times for $5 \mathrm{~min}$ each on a shaking bed with TBST at room temperature. The secondary antibody (Wuhan Goodbio Technology Co., Ltd.) was diluted $(1: 3,000)$ with TBST, and incubated for $30 \mathrm{~min}$. The PVDF membranes were washed with TBST 3 times for 5 min again. After full access to substrate working solution, developments and fixing, the gray scale was analyzed using the Alpha software processing system (Alpha Innotech Corp., San Leandro, CA, USA).

Statistical analysis. All data are expressed as the means \pm standard error of the mean and analyzed using GraphPad Prism version 6.01 (GraphPad Software, Inc., San Diego, CA; USA).
Statistical signifiance was determined using a Student's t-test, and a value of $\mathrm{p}<0.05$ was considered to indicate a statistically significant difference.

\section{Results}

Optimal LPS and GTS-21 concentration. In order to select the optimal concentrations of LPS and GTS-21, we designed the LPS and GTS concentration gradient. The levels of TNF- $\alpha$ and HMGB1 in the cells were examined by ELISA in order to determine the optimal concentration of LPS needed to induce maximal levels of TNF- $\alpha$ and HMGB1 and the optimal concentration of GTS-21 needed to reduce the levels of TNF- $\alpha$ and HMGB1. Following incubation for $24 \mathrm{~h}$ at $37^{\circ} \mathrm{C}$, we stimulated the RAW264.7 cells with LPS using the 30,50 and $80 \mathrm{ng} / \mathrm{ml}$ concentration gradients following pre-treatment with GTS-21 using the 6,8 and $10 \mu \mathrm{g} / \mathrm{ml}$ concentration gradients half an hour earlier. The results suggested that macrophages stimulated with LPS $50 \mathrm{ng} / \mathrm{ml}$ expressed more TNF- $\alpha$ and HMGB1 than the other groups; thus, this concentration was considered ideal (Fig. 1A). When the macrophages were stimulated with $50 \mathrm{ng} / \mathrm{ml}$ LPS and 3 different concentrations of GTS-21, the decrease in the expression of TNF- $\alpha$ and HMGB1 was greatest at $8 \mu \mathrm{g} /$ $\mathrm{ml}$ of GTS-21 (Fig. 1B). The optimal GTS-21 concentration for treatment was $8 \mu \mathrm{g} / \mathrm{ml}$, as this concentration achieved optimal inhibitory effects.

Upregulated miRNA targets in microarray analysis. In the heatmap shown in Fig. 2, each row represents a single miRNA, and each column represents a plasma sample. The legend on the right indicates the miRNA representing the corresponding row. The relative miRNA expression is displayed according to the color scale: red indicates upregulation; green indicates downregulation, as previously described (19).

Differentially expressed miRNAs were identified through fold change (FC). Among the different miRs (miR-205-5b, miR-196a and miR-193b), miR-205 was highly expressed in the GTS-21 group, and its levels were 18.478138-fold those of the LPS group, and 14.27163-fold those of the control group.

Optimal dosage of GTS-21 in mice. The mice $(\mathrm{n}=6)$ were intraperitoneally injected with GTS-21 (2, 4 and $6 \mathrm{mg} / \mathrm{kg})$ or 

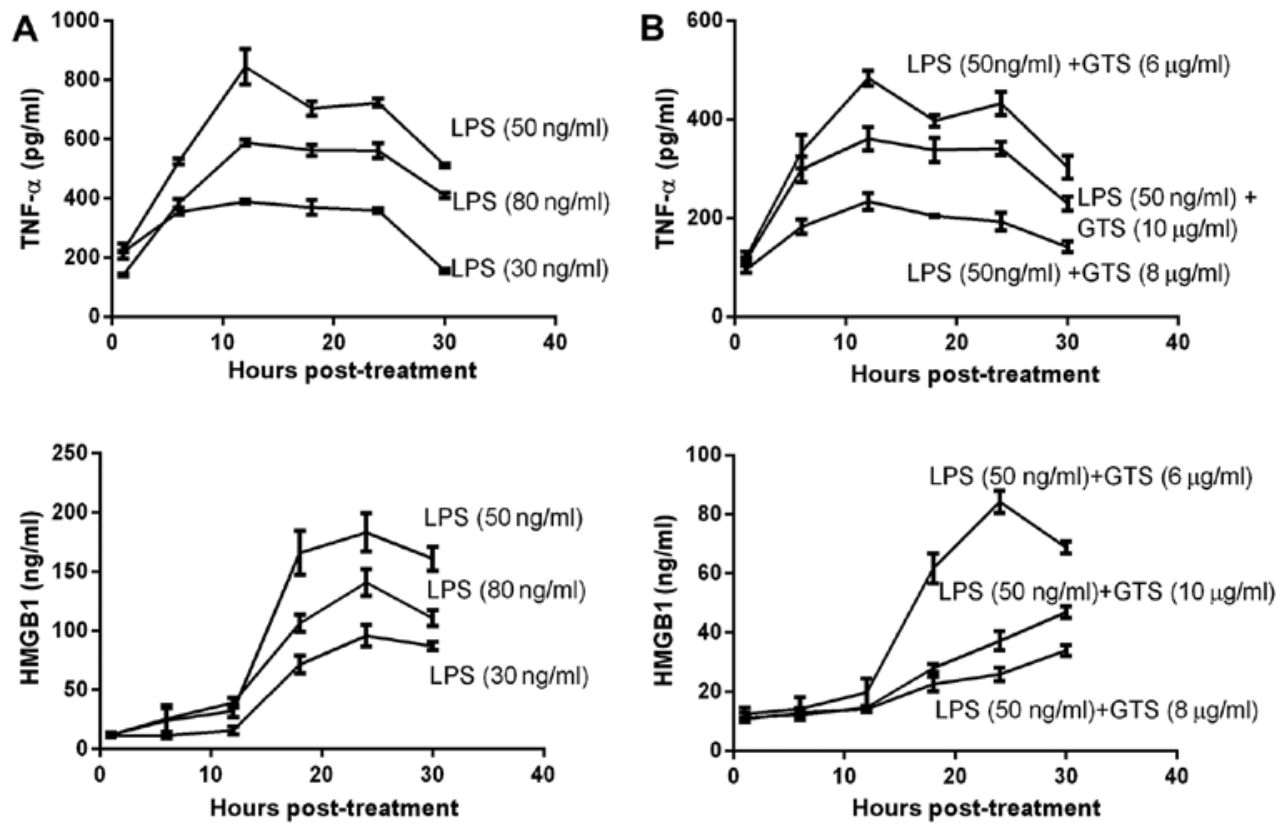

Figure 1. GTS-21 inhibits cellular tumor necrosis factor (TNF)- $\alpha$ and high mobility group box (HMGB)1 release. The optimal dose of LPS is $50 \mathrm{ng} / \mathrm{ml}$, and that of GTS-21 is $8 \mu \mathrm{g} / \mathrm{ml}$. (A) Time courses of TNF- $\alpha$ and HMGB1 induction in RAW264.7 cells stimulated with LPS 30, $50 \mathrm{and} 80 \mathrm{ng} / \mathrm{ml}$. (B) Time courses of TNF- $\alpha$ and HMGB1 induction in RAW264.7 cells treated with LPS $50 \mathrm{ng} / \mathrm{ml}$ and different concentrations of GTS-21 $(6,8 \mathrm{and} 10 \mu \mathrm{g} / \mathrm{ml})$.

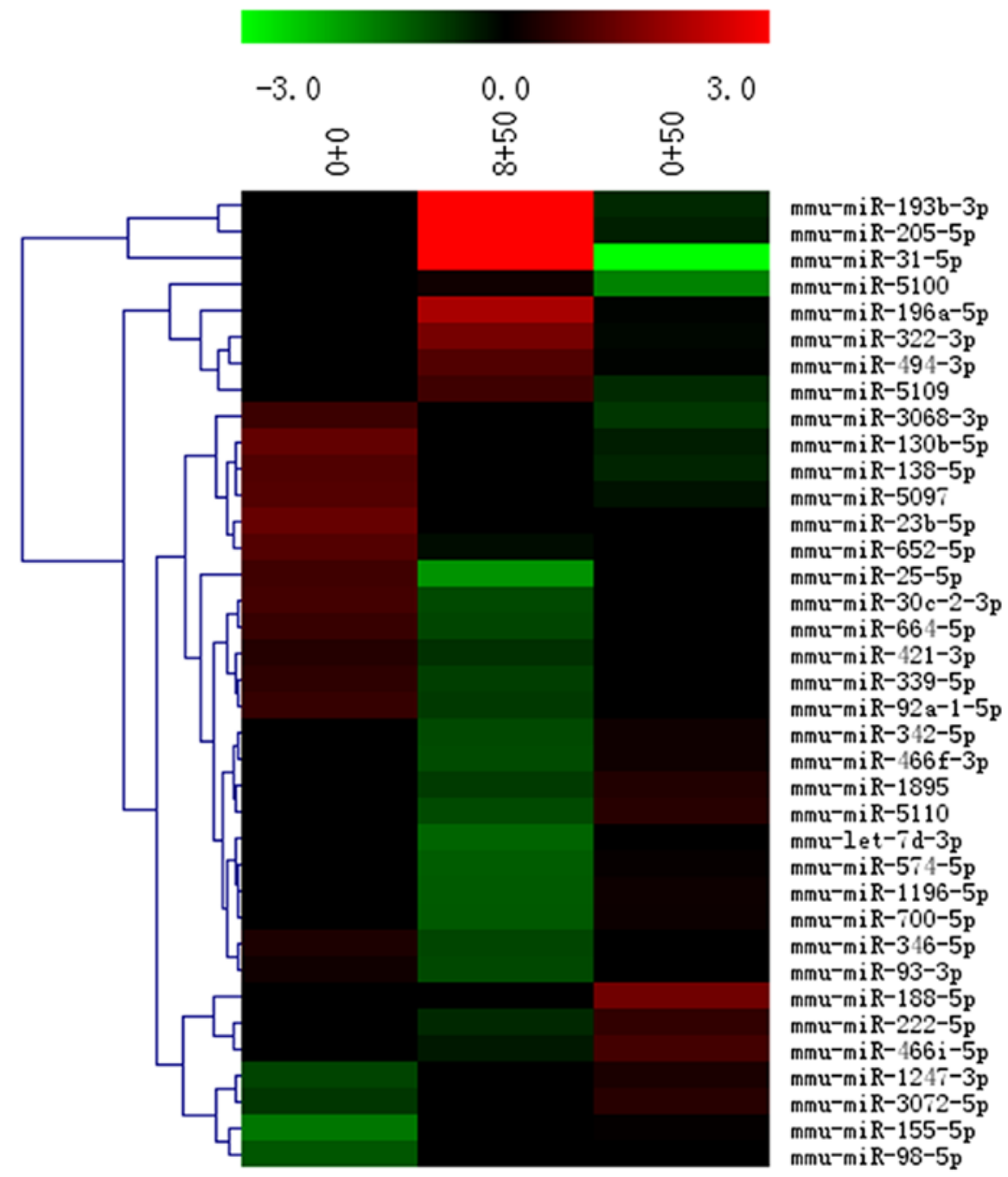

Figure 2. Heatmap showing 3 differentially expressed (fold change $\geq 2.0$ ) miRNAs from homogeneous RAW264.7 samples. The numbers with $(0+0)$ indicate the control; numbers with $(0+50)$ indicate LPS-stimulated cells, numbers with $(8+50)$ indicate GTS-21-treated cells. 

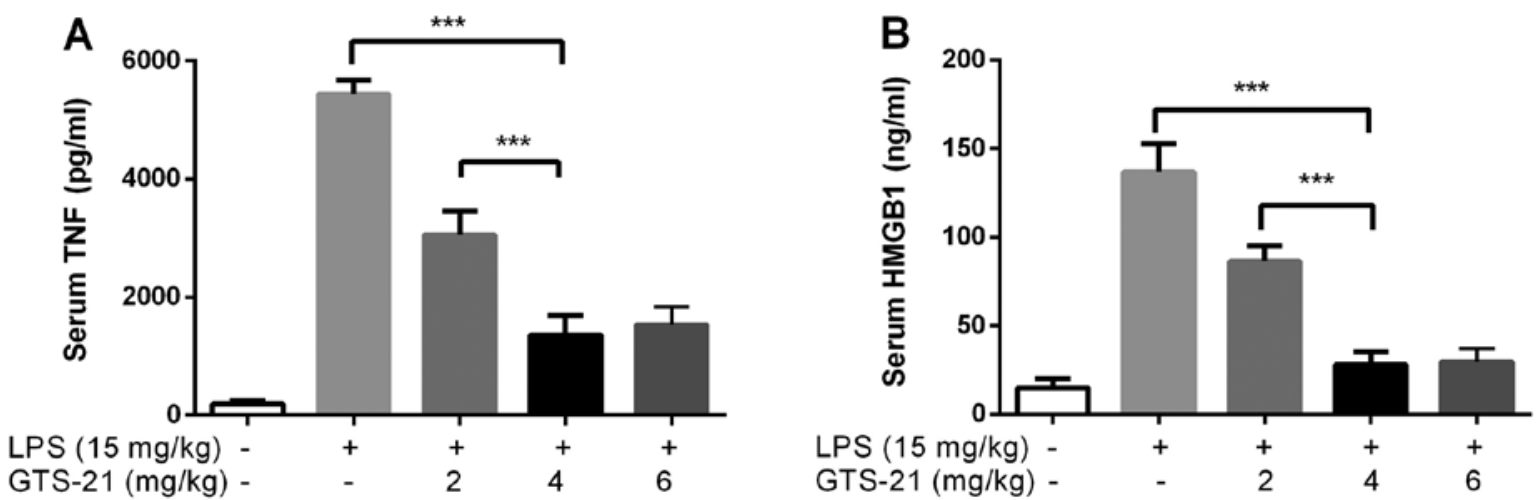

Figure 3. GTS-21 inhibits circulatory tumor necrosis factor (TNF)- $\alpha$ and high mobility group box (HMGB)1 release in endotoxemic mice. The optimal dose of GTS-21 is $4 \mathrm{mg} / \mathrm{kg}$. (A) Serum TNF- $\alpha$ levels were analyzed by ELISA. (B) Serum HMGB1 levels were analyzed by ELISA. $\mathrm{n}=6$ mice per group. Data are the means $\pm \mathrm{SD} ;{ }^{* * * *} \mathrm{p}<0.001$ vs. LPS-treated group.

A
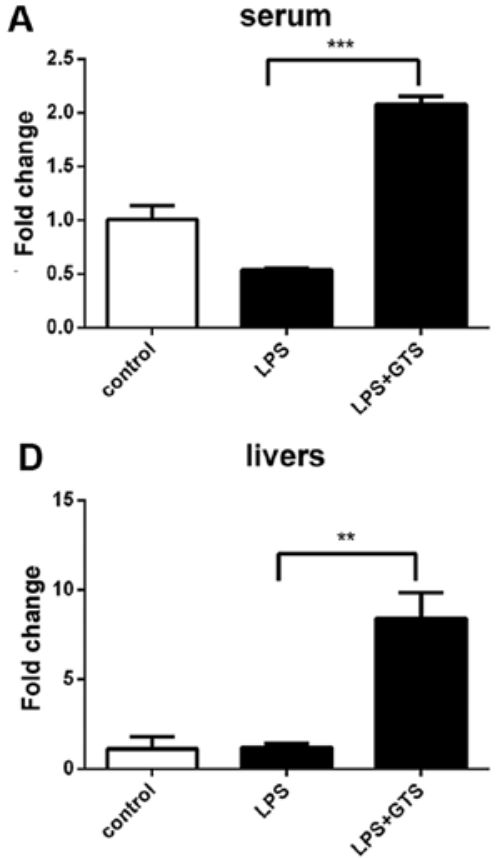

B

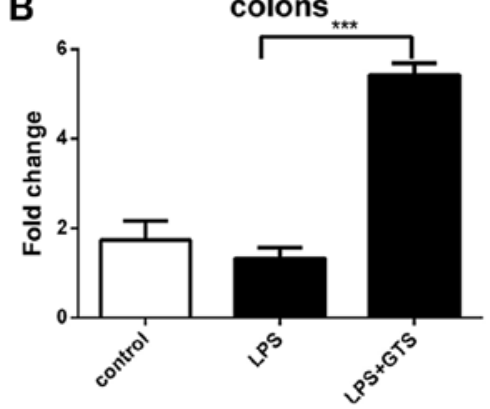

E

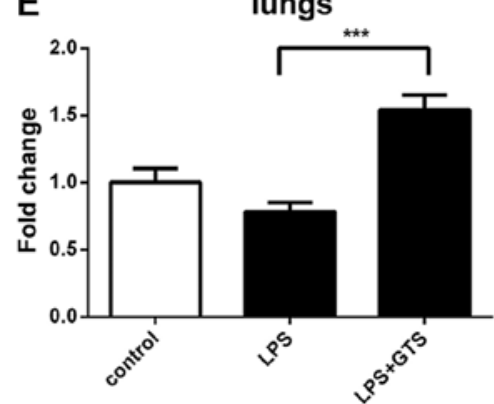

C

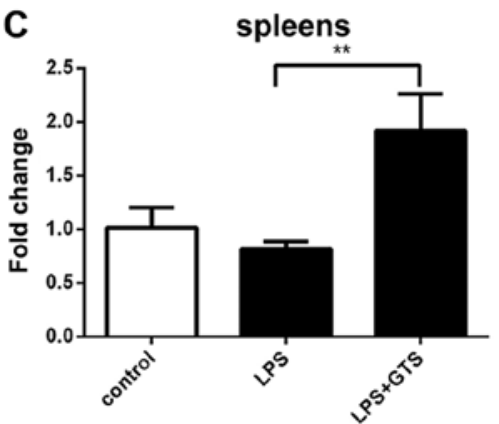

F

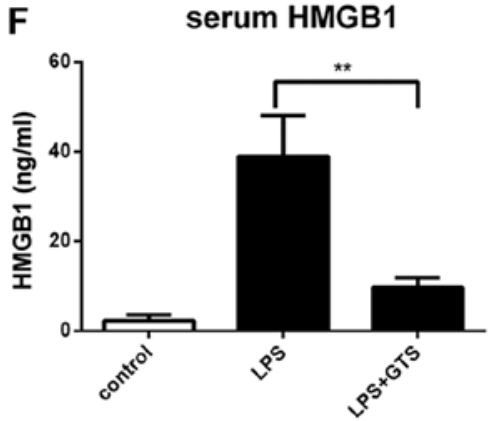

Figure 4. RT-qPCR analysis of miR-205-5b expression in (A-E) different tissues from BALB/c mice. (F) The serum concentration of high mobility group box (HMGB)1. ${ }^{* *} \mathrm{p}<0.01,{ }^{* * * *} \mathrm{p}<0.001$.

saline 30 min prior to LPS administration. The serum TNF- $\alpha$ and HMGB1 levels were analyzed 12 and $24 \mathrm{~h}$ later. The ideal dose of GTS-21 was $4 \mathrm{mg} / \mathrm{kg}$ as it induced the most prominent inhibitory effects on TNF- $\alpha$ and HMGB1 expression (Fig. 3).

Expression profiles of miR-205-5p in mice with sepsis. The expression levels of miR-205-5p targets in the serum, livers, colons, lungs and spleen were quantified by RT-qPCR to verify the upregulation detected in the samples of GTS-21-treated septic mice. The miR-205-5p levels were not similar in the different organs (Fig. 4A-E). The levels of miR-205-5p in the different mouse organs were as follows: serum (LPS vs. control $\mathrm{p}=0.0033$; GTS vs. control $\mathrm{p}<0.0002$; GTS vs. LPS $\mathrm{p}=0.0001$ ), colon (LPS vs. control $\mathrm{p}=0.2915$; GTS vs. control $\mathrm{p}<0.0002$; GTS vs. LPS $p=0.0001$ ); spleen (LPS vs. control $p=0.1640$; GTS vs. control $\mathrm{p}<0.0157$; GTS vs. LPS $\mathrm{p}=0.0054)$; liver (LPS vs. control $\mathrm{p}=0.8472$; GTS vs. control $\mathrm{p}<0.0015$; GTS vs. LPS $\mathrm{p}=0.0011$ ); and lungs (LPS vs. control $\mathrm{p}=0.0364$; GTS vs. control $\mathrm{p}<0.0032$; GTS vs. LPS p=0.0005) (Fig. 4A-E). In general, treatment with GTS-21 induced a significant increase in miR-205-5p expression.

The serum concentration of HMGB1 (LPS vs. GTS $\mathrm{p}=0.0054$; LPS vs. control $\mathrm{p}=0.0022 ;$ LPS + GTS vs. control $\mathrm{p}=0.0063$ ) (Fig. 4F) was significantly increased following the administration of LPS. HMGB1 expression was markedly decreased in serum following treatment with GTS-21 (Fig. 4F).

miR-205-5b attenuates the LPS-induced increase in HMGB1 expression. We first confirmed that transfection with miR-205-5b mimics significantly increased miR-205-5b expression in the cells (Fig. 5A). When the RAW264.7 cells were transfected with the miR-205 mimics, or negative control for $24 \mathrm{~h}$, as shown in Fig. 5, HMGB1 protein expression was altered $(\mathrm{p}<0.05)$. Western blot analysis of HMGB1 protein expression revealed 
A
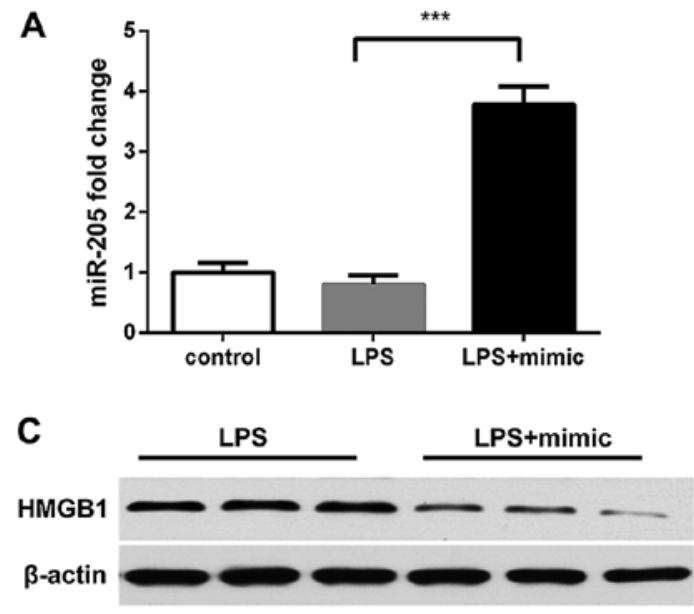
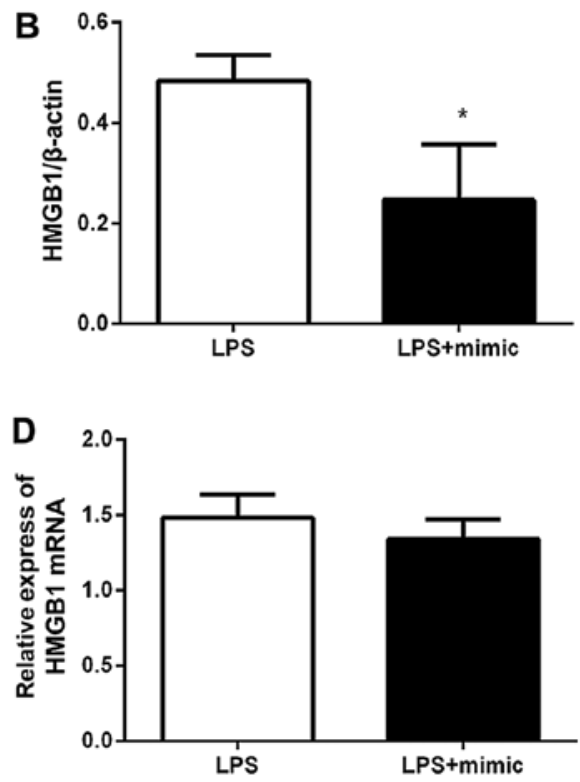

Figure 5. RAW264.7 cells were stimulated with LPS or transfected with the miR-205-5b mimic. (A) miR-205 expression was significantly increased follwoing transfection with miR-205-5b mimic. (B and C) When miR-205 was overexpressed, the protein expression of high mobility group box (HMGB)1 was low in the RAW264.7 cells; (D) however, HMGB1 mRNA expression was not significantly altered in the two groups. "p $<0.05,{ }^{* * *} \mathrm{p}<0.001$.
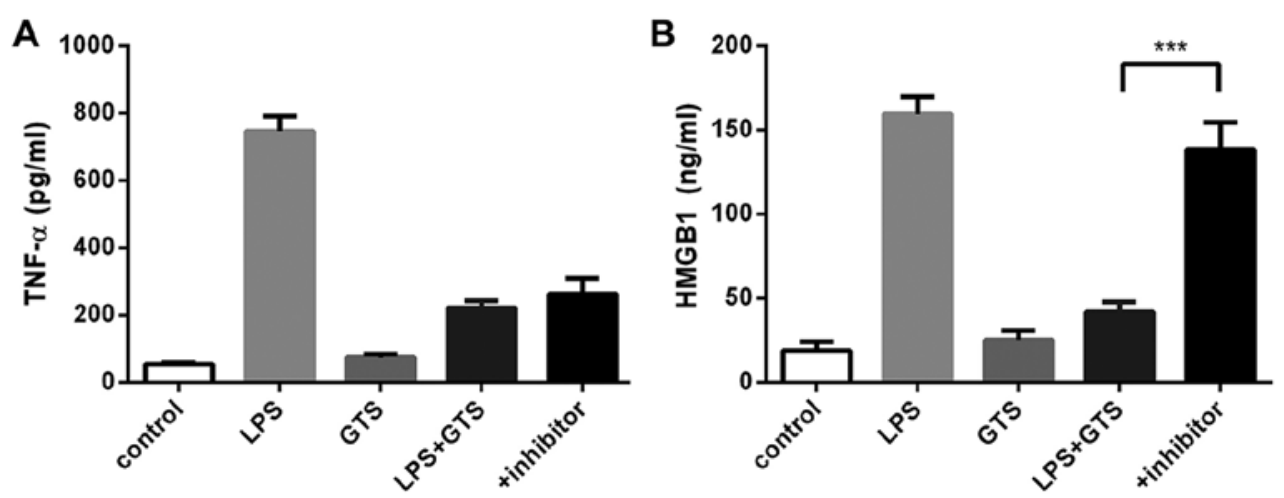

Figure 6. RAW264.7 cells were stimulated with LPS or GTS-21 or LPS + GTS-21, or treated with the miR-205-5b inhibitor and stimulated with LPS + GTS-21 The levels of tumor necrosis factor (TNF)- $\alpha$ and high mobility group box (HMGB)1 were determined at 12 and 24 h, respectively. Following transfection with the inhibitor, the RAW264.7 cells were stimulated with LPS and GTS-21, and (A) TNF- $\alpha$ expression was not reduced $12 \mathrm{~h}$ later; however, (B) HMGB1 expression was increased $24 \mathrm{~h}$ later; $\mathrm{n}=3$ experiments; data are the means $\pm \mathrm{SD} ;{ }^{* * *} \mathrm{p}<0.001$.

that the HMGB1 levels in the group transfected with miR-205-5b mimics were significantly lower than those in the negative control-transfected group ( $\mathrm{p}=0.0280$; Fig. $5 \mathrm{~B}$ and C). However, the miR-205-5b mimics did not affect the HMGB1 mRNA level ( $\mathrm{p}=0.2896$; Fig. 5D).

Transfection with the miR-205 inhibitor did not affect the GTS-21-induced suppression of the expression of TNF- $\alpha$ (Fig. 6A); however, the miR-205 inhibitor increased HMGB1 expression $24 \mathrm{~h}$ later (Fig. 6B).

\section{Discussion}

CAP mediates the inhibition of the production of inflammatory cytokines, including TNF- $\alpha$, nuclear factor $(\mathrm{NF})-\kappa B$ and HMGB1 in sepsis (3). It acts similarly in other inflammatory syndromes, such as arthritis and viral myocarditis $(20,21)$.

The mechanisms of action of CAP entail $\alpha 7 n$ AchR activation by electrical vagal stimulation or pharmacological agonists. Electrical vagal stimulation is impracticable in sepsis. GTS-21, a selective partial $\alpha 7 \mathrm{nAchR}$ agonist (22), has been proven to effectively reduce the inflammatory reaction and improve prognosis in animals (23-25). Similar to previous studies (22), our findings suggest that GTS-21 suppresses TNF- $\alpha$ and HMGB1 expression in a dose-dependent manner in experiments using mouse macrophages. The curves indicated the optimal concentration of GTS-21 as $8 \mu \mathrm{g} / \mathrm{ml}$ for marophages.

Mammalian miRNAs have emerged as meaningful modulators of cellular function in different organ systems since their discovery (10). Previous studies have shown that miR-124 mediates the cholinergic anti-inflammatory action against early inflammatory factors, including TNF- $\alpha$ maturation by TACE and IL- 6 transcription by targeting STAT3 (17); however, it is unknown whether miRNAs affect HMGB1. To elucidate the mechanisms underlying the cholinergic antiinflammatory activity against one of the most important late inflammatory factors, which correlates with prognosis (7), we performed miRNA microarray analysis to identify potential miRNAs involved. To the best of our knowledge, our study 
has confirmed for the first time that miR-205-5b expression significantly increased following the activation of $\alpha 7 \mathrm{nAchR}$ in macrophages.

In vitro experiments were more credible as they ruled out the possibility of HMGB1 release from the necrotic tissue. We reported that LPS-stimulated RAW264.7 cells transfected with miR-205-5b mimics displayed a low HMGB1 expression, whereas the expression of TNF- $\alpha$ was not altered. However, transfection with miR-205-5b inhibitor neutralized the effects of GTS-21 on HMGB1 expression. Therefore, our results indicate that miR-205-5b targets HMGB1 expression in the CAP. The results of RT-qPCR demonstrated that miR-205-5b mimics did not affect the HMGB1 mRNA levels, with no significant differences observed between the mimics- and negative control-transfected groups, suggesting a post-transcriptional regulation.

In animal experiments, miR-205-5b expression in the LPS group exhibited a decrease, although this was not significant in the different tissues. This indicates that LPS cannot suppress the expression of miR-205-5b. miR-205-5b targets different proteins in different pathophysiologies (26-29). In this study, we first found that following the activation of CAP, superfluous miR-205-5b suppressed HMGB1 via the transcriptional inhibition of HMGB1 in serum. Decreased HMGB1 expression leads to sharply lowered blood HMGB1 levels.

In conclusion, miR205-5b upregulation suppresses HMGB1 expression in cells and tissues in sepsis. The regulatory mechanisms involved include the suppression of HMGB1 at the post-transcriptional level. miR-205-5b may thus be a potential therapeutic target for the treatment of inflammatory diseases and a possible novel therapeutic strategy against late sepsis.

\section{Acknowledgements}

The present study was financially supported by the National Natural Science Foundation of China (no. 30972852).

\section{References}

1. Kang R, Chen R, Zhang Q, Hou W, Wu S, Cao L, Huang J, Yu Y, Fan XG, Yan Z, et al: HMGB1 in health and disease. Mol Aspects Med 40: 1-116, 2014.

2. Tracey KJ: The inflammatory reflex. Nature 420: 853-859, 2002.

3. Pavlov VA, Wang H, Czura CJ, Friedman SG and Tracey KJ: The cholinergic anti-inflammatory pathway: a missing link in neuroimmunomodulation. Mol Med 9: 125-134, 2003.

4. Silman NJ: Rapid diagnosis of sepsis using biomarker signatures. Crit Care 17: 1020, 2013.

5. Lyle NH, Pena OM, Boyd JH and Hancock R: Barriers to the effective treatment of sepsis: antimicrobial agents, sepsis definitions, and host-directed therapies. Ann NY Acad Sci 1323: 101-114, 2014.

6. Xu L, Bao H, Si Y and Wang X: Effects of dexmedetomidine on early and late cytokines during polymicrobial sepsis in mice. Inflamm Res 62: 507-514, 2013.

7. Charoensup J, Sermswan RW, Paeyao A, Promakhejohn S, Punasee S, Chularari C, Krabkraikaew S, Lertanekawattana S and Wongratanacheewin S: High HMGB1 level is associated with poor outcome of septicemic melioidosis. Int J Infect Dis 28: 111-116, 2014.

8. Guo ZS, Liu ZQ, Bartlett DL, Tang DL and Lotze MT: Life after death: targeting high mobility group box 1 in emergent cancer therapies. Am J Cancer Res 3: 1-20, 2013.

9. Wang H, Liao H, Ochani M, Justiniani M, Lin X, Yang L, Al-Abed Y, Wang H, Metz C, Miller EJ, et al: Cholinergic agonists inhibit HMGB1 release and improve survival in experimental sepsis. Nat Med 10: 1216-1221, 2004.
10. O'Connell RM, Rao DS and Baltimore D: microRNA regulation of inflammatory responses. Annu Rev Immunol 30: 295-312, 2012.

11. Moon HG, Yang J, Zheng Y and Jin Y: miR-15a/16 regulates macrophage phagocytosis after bacterial infection. J Immunol 193: 4558-4567, 2014.

12. Chatterjee V, Beard RS Jr, Reynolds JJ, Haines R, Guo M, Rubin M, Guido J, Wu MH and Yuan SY: MicroRNA-147b regulates vascular endothelial barrier function by targeting ADAM15 expression. PLoS One 9: e110286, 2014.

13. Wang HJ, Deng J, Wang JY, Zhang PJ, Xin Z, Xiao K, Feng D, Jia YH, Liu YN and Xie LX: Serum miR-122 levels are related to coagulation disorders in sepsis patients. Clin Chem Lab Med 52: 927-933, 2014.

14. Tacke F, Roderburg C, Benz F, Cardenas DV, Luedde M, Hippe HJ, Frey N, Vucur M, Gautheron J, Koch A, et al: Levels of circulating miR-133a are elevated in sepsis and predict mortality in critically ill patients. Crit Care Med 42: 1096-1104, 2014.

15. Pavlov VA and Tracey KJ: Controlling inflammation: the cholinergic anti-inflammatory pathway. Biochem Soc Trans 34: 1037-1040, 2006.

16. Wang H, Yu M, Ochani M, Amella CA, Tanovic M, Susarla S, Li JH, Wang H, Yang H, Ulloa L, et al: Nicotinic acetylcholine receptor alpha7 subunit is an essential regulator of inflammation. Nature 421: 384-388, 2003.

17. Sun Y, Li Q, Gui H, Xu DP, Yang YL, Su DF and Liu X: MicroRNA-124 mediates the cholinergic anti-inflammatory action through inhibiting the production of pro-inflammatory cytokines. Cell Res 23: 1270-1283, 2013.

18. Musumeci D, Roviello GN and Montesarchio D: An overview on HMGB1 inhibitors as potential therapeutic agents in HMGB1-related pathologies. Pharmacol Ther 141: 347-357, 2014.

19. Jia SZ, Yang Y, Lang J, Sun P and Leng J: Plasma miR-17-5p, miR-20a and miR-22 are down-regulated in women with endometriosis. Hum Reprod 28: 322-330, 2013.

20. Cheng Z, Li-Sha G, Jing-Lin Z, Wen-Wu Z, Xue-Si C, Xing-Xing $\mathrm{C}$ and Yue-Chun L: Protective role of the cholinergic anti-inflammatory pathway in a mouse model of viral myocarditis. PLoS One 9: e112719, 2014.

21. Koopman FA, Schuurman PR, Vervoordeldonk MJ and Tak PP: Vagus nerve stimulation: a new bioelectronics approach to treat rheumatoid arthritis? Best Pract Res Clin Rheumatol 28: 625-635, 2014.

22. Sitapara RA, Antoine DJ, Sharma L, Patel VS, Ashby CR Jr, Gorasiya S, Yang H, Zur M and Mantell LL: The $\alpha 7$ nicotinic acetylcholine receptor agonist GTS-21 improves bacterial clearance in mice by restoring hyperoxia-compromised macrophage function. Mol Med 20: 238-247, 2014.

23. Cai B, Chen F, Ji Y, Kiss L, de Jonge WJ, Conejero-Goldberg C, Szabo C, Deitch EA and Ulloa L: Alpha7 cholinergic-agonist prevents systemic inflammation and improves survival during resuscitation. J Cell Mol Med 13 (9B): 3774-3785, 2009.

24. Kox M, Pompe JC, Peters E, Vaneker M, van der Laak JW, van der Hoeven JG, Scheffer GJ, Hoedemaekers CW and Pickkers P: $\alpha 7$ nicotinic acetylcholine receptor agonist GTS-21 attenuates ventilator-induced tumour necrosis factor- $\alpha$ production and lung injury. Br J Anaesth 107: 559-566, 2011.

25. Pavlov VA, Ochani M, Yang LH, Gallowitsch-Puerta M, Ochani K, Lin X, Levi J, Parrish WR, Rosas-Ballina M, Czura CJ, et al: Selective alpha7-nicotinic acetylcholine receptor agonist GTS-21 improves survival in murine endotoxemia and severe sepsis. Crit Care Med 35: 1139-1144, 2007.

26. Zhang P, Wang L, Rodriguez-Aguayo C, Yuan Y, Debeb BG, Chen D, Sun Y, You MJ, Liu Y, Dean DC, et al: miR-205 acts as a tumour radiosensitizer by targeting ZEB1 and Ubc13. Nat Commun 5: 5671, 2014.

27. Lin D, Halilovic A, Yue P, Bellner L, Wang K, Wang L and Zhang C: Inhibition of miR-205 impairs the wound-healing process in human corneal epithelial cells by targeting KIR4.1 (KCNJ10). Invest Ophthalmol Vis Sci 54: 6167-6178, 2013.

28. Orang AV, Safaralizadeh R, Hosseinpour Feizi MA and Somi MH: Diagnostic and prognostic value of miR-205 in colorectal cancer. Asian Pac J Cancer Prev 15: 4033-4037, 2014.

29. Qiao W, Chen L and Zhang M: MicroRNA-205 regulates the calcification and osteoblastic differentiation of vascular smooth muscle cells. Cell Physiol Biochem 33: 1945-1953, 2014. 